\title{
Developing (Transformative) Environmental and Sustainability Education in Classroom Practice
}

\author{
Nicola Walshe ${ }^{1, *(D)}$ and Louise Sund ${ }^{2}$ (D) \\ 1 Department of Curriculum, Pedagogy and Assessment, UCL Institute of Education, London WC1H 0AL, UK \\ 2 School of Humanities, Education and Social Sciences, Örebro University, SE-70182 Örebro, Sweden; \\ louise.sund@mdh.se \\ * Correspondence: n.walshe@ucl.ac.uk
}

Citation: Walshe, N.; Sund, L. Developing (Transformative) Environmental and Sustainability Education in Classroom Practice. Sustainability 2022, 14, 110. https:// doi.org/10.3390/su14010110

Received: 8 December 2021

Accepted: 15 December 2021

Published: 23 December 2021

Publisher's Note: MDPI stays neutral with regard to jurisdictional claims in published maps and institutional affiliations.

Copyright: (c) 2021 by the authors. Licensee MDPI, Basel, Switzerland. This article is an open access article distributed under the terms and conditions of the Creative Commons Attribution (CC BY) license (https:// creativecommons.org/licenses/by/ $4.0 /)$.
We are writing this editorial in the weeks preceding COP26; as we do, wall-to-wall coverage of events and speculation of what might (or might not) be achieved across mainstream and social media channels suggest that awareness of the impacts of climate change on planetary sustainability and human and nonhuman forms of life has never been higher. Alongside this, perhaps emerging from concurrent social movements, such as Black Lives Matter, there seems to be a growing understanding that the scale of the environmental crisis is magnified by global warming's interaction with a host of other social, economic and political factors, thereby 'multiplying' the risk of poverty, disease, food insecurity, political instability, conflict, to name but a few. There is also acknowledgement that 'Global South' economies often bear the brunt of global climate change, with warming temperatures and unpredictable weather patterns driving economic hardship, food insecurity and migration. However, despite the reality of climate change and its increasingly significant global impacts, the discourse around climate change and, more broadly, sustainable development is still varied. Even within the majority who accept that climate change is taking place, there are some commentators who controversially argue that a climate apocalypse is unavoidable, while others maintain that there is still a small window of opportunity to act to avert total climate chaos. In this way, children and young people are growing up in uncertain, precarious and potentially confusing times, as the social, cultural and environmental effects of global climate change begin to permeate their everyday lives and communities and they grapple with various futures presented to them and what might be done to achieve them. As such, environmental and sustainability education (ESE) has a critical role to play, for example, in ensuring that it forms part of a broader response to the global effort to reduce greenhouse gas emissions in order to reduce the likelihood of further catastrophic climate change; however, it also needs to address emotional responses, such as eco-anxiety, and empower children and young people to address environmental issues, such as climate change, both individually and collectively, now and in the future. In this way, it might become truly transformative.

Perhaps in response to some of the challenges exemplified by the complexity of climate change education, teaching for ESE has been described as a wicked problem with multiple complex, context-based and uncontrollable variables that affect learning [1]. This complexity is exacerbated by its inextricable links to a wider range of unprecedented global challenges, such as the increasingly stark eruption of inequalities precipitated by continuing economic fallout from the Global Financial Crisis; the migratory crisis driven by the cumulative action of wars and climate change; and racial inequalities, xenophobia, and white supremacy. As a result, there remains discussion as to what the pedagogical approaches for ESE should be, both within and beyond formal educational contexts, such as schools. Sterling (2010/11) argued that in order to develop truly effective ESE pedagogies, we should look to transformative learning theory. Transformative learning is a potentially important aspect of ESE as it encourages learners to move beyond the simple acquisition of knowledge to a deeper and more holistic learning experience which has the potential 
to change the way they understand and conceptualise their world. As such, it signifies a change in worldview for the learner which has greater potential to impact the way they live within it. More specifically, Mezirow defined transformative learning as a process whereby [2] (p. 7):

"we transform our taken-for-granted frames of reference to make them more inclusive, discriminating, open, [changeable], and reflective so that they may generate beliefs and opinions that will prove more true or justified to guide action".

In this way, Mezirow's suggestion is that transformative learning involves a shift in consciousness which affects our deeper level of understanding and, perhaps more importantly for ESE, a change in our behaviour. With this in mind, Sterling referred to three orders of learning and change [3]:

- $\quad$ First-order learning refers to doing 'more of the same', perhaps in a slightly more efficient way, without examining the values that inform that action. Due to its contentled nature, the majority of learning within formal education settings, such as schools, is often seen as first-order learning, taught through transmissive pedagogies with little critical reflection to challenge the beliefs of the learners.

- Second-order learning refers to significant changes in thinking based on the examination of assumptions and values through meta-cognitive processes. This type of learning can be more challenging as it involves the critical reflection of knowledge, values and beliefs; for this reason, it is considered to be more permanent.

- Third-order learning is epistemic, in that it causes us to profoundly challenge and reconstruct our deeper held beliefs and values.

For some, transformative learning would facilitate a shift from first-order to secondorder learning, whereas, for others, it necessarily equates to the change in worldview depicted by third-order learning. For both, what is significant is that it often involves resistance on the part of the learner because it challenges existing understanding and beliefs, and often requires a reconstruction of meaning, which can cause discomfort on the part of an individual which can be difficult if not appropriately supported. In this way, it is not enough for students to learn about climate change and its associated problems; what is needed is education aimed at a shift in perspective; as Sterling put it: "Sustainability is not just another issue to be added to an overcrowded curriculum, but a gateway to a different view of curriculum, of pedagogy, of organisational change, of policy and particularly of ethos" [4] (p. 50).

While this preference for third-order learning might be seen as being desirable within the context of ESE, there are criticisms of this approach; by definition, transformative learning is promoted as being good, such that we should move towards new frames of reference which are better than others; this definition can be criticised as being culturally bound and reflect Western values and beliefs that anyone can achieve anything if they only work hard enough to overcome whatever barriers they face. As such, transformative learning can be seen as a colonial construct which does not appropriately reflect the sociocultural and historical contexts in which learning is taking place. Andreotti further warned against this, suggesting that as [5]:

"The modern/colonial desire to know the world to control it (Gandhi 1999) prevents us from relating to the world in its full complexity, plurality, movement, entanglement and indetermination. For this desire to be interrupted, it first needs to be identified within ourselves and that is where images, metaphors, and strategic intellectual distinctions become indispensable in the context of depth education." (pp. 147-148)

For this reason, it is important to assert the nature of transformative learning, rather than indoctrination, which encourages students to reflect on the purpose and mechanism of ESE with a view for the critical engagement with, rather than pure promotion of, sustainable development. Andreotti described this as depth education, 'the kind of education that 
addresses disavowals and denials, centers neither the teacher, nor the learner, but the world itself' [5] (p. 147). This would appear to resonate with what Sterling described as third-order learning [3].

While Sterling suggested that transformative learning is difficult for teachers to facilitate, there is some discussion within the literature as to what learning approaches or pedagogical practice might be transformational [3]. Mezirow originally saw three constructs as being central: critical reflection for deeper understanding and action, dialogue with others and experience [6]. In this way, transformational learning approaches align well with participatory, place-based, enquiry-based pedagogies which are inherently studentcentred and include a range of strategies, as well as critical pedagogies which generate a questioning frame of mind, a reflective approach to our actions and the actions of others, and a commitment to do something. Such pedagogies should also provide children and young people with the opportunity to surface problematic aspects of our denial of the seriousness of climate change and the complexity of the multiple problems we need to face together and how we are not part of these problems, but also part of the solutions. However, this uncertainty is what led us to developing the theme of this special issue, to explore the pedagogy and practice of ESE in schools, with a particular focus on transformative pedagogies.

Across the volume, there are wide-ranging interpretations of and approaches to transformative pedagogies and how they intersect. In the first article, Niranjan Casinder discusses a risk with a monocultural definition of sustainability and argues for a remodelled approach to ESE that is founded on transculturalism and in touch with the cultural complexity of contemporary societies. A transcultural expertise or capacity is something that ESE teachers need to develop and acquire to adapt transformative and effective ESE pedagogies that is up-to-date with students' realities. A transculturalist approach to teaching entails a shift in attitude on the part of the teacher and builds on knowing about the nature of cultures and communication but also relating to this knowledge and considering their role in ESE. Casinder describes the development of transcultural capacity in teachers as an 'ongoing maturation through experience and professional learning' where teachers seek to develop a more conscious awareness of cultural nuance as a point of opportunity. Thus, if we want to develop transcultural capacity in ESE educators and a transformative foundation for teacher education and professional development, we need to stress that cultural perspectives are contextual and that sustainability exists as a culturally relative concept, as well as to highlight the existence of variations without feeling the need to homogenise ESE.

The second article is written by Brian McCullough and Jamee Pelcher and focuses on the need to equip students to address emerging issues regarding sustainability in the sports sector through both mentoring and student-instructor conversations. More specifically, they use collaborative reflections to evaluate transformational learning experiences to assess new levels of awareness, critical thinking and practical applications to make a change within a sports organisation to pursue environmental sustainability initiatives. Transformative sustainably learning (TSL) is described as a form of experiential learning that grew from traditions of sustainability education and transformative education and uses hands-on experiences to drive environmental or social change. This holistic approach to transformational learning experiences focuses on involving students' heads (engage), hearts (enable) and hands (enact) to inspire and cultivate critical thinking, relational knowing and practical applications. The authors claim that it might be helpful in the classroom to promote understanding and to encourage deeper reflection.

In the third article, Elisabeth Rushton takes as a starting point the call for educators to use participatory, interdisciplinary and affect-driven approaches when responding to ethical and political climate change issues. She investigates secondary school trainee geography teachers and the ways in which teacher training programmes provide student teachers with opportunities to develop their professional identities in the context of ESE or 'to build ESE identities'. Rushton found that the trainee teachers experienced tension, conflict 
and frustration when enacting their identities and that they used a range of approaches when implementing ESE in the classroom, e.g. valuing critical thinking, incorporating playful approaches, and foregrounding personal connections with the environment which adapt and endure during professional challenge, rather than moving away from ESE. The study also shows that teachers need guidance regarding identity formation and how this interlinks with practice. This work points to important implications for practice for institutions that undertake professional development for teachers, including pre-service teacher education.

In the fourth article, Per Sund and Niklas Gericke present and describe a systematic and thematic research review of different 'selective traditions', or the variety of ways of teaching about environmental and sustainability issues. The term 'selective traditions' functions as a frame of reference within a specific culture or discourse when teachers select a certain approach to knowledge and a certain educational praxis. Each tradition represents different answers as to what constitutes good teaching and relates to teachers' approaches to the content, methods and purposes of environmental and sustainability education. In this study, Sund and Gericke focus on the specific functions and consequences of selective traditions for research and practice in ESE. Seven functions that are valuable for the development of ESE teaching and research are identified, among them: to analyse empirical work, to evaluate ESE teaching over time, to visualise the context-sensitive nature of teaching, to use as a reflective framework of one's own teaching, and to promote specific teaching outcomes. The authors claim that the functions are useful in the systematic development and transformation of practice-oriented ESE teaching in teacher education and in-service training as they can illuminate the many aspects to consider when discussing and analysing ESE teaching, e.g., philosophical and educational responses to development, the root causes of developmental challenges, disciplinary traditions, curriculum changes, as well as external pressures and market forces.

In the fifth article, Johan Öhman and Louise Sund propose a model that describes and frames sustainability commitment, based on didactic theory and pragmatic philosophy, and informed by empirical studies on ESE practice. The model stresses the intellectual, emotional and practical aspects of sustainability as these are crucial for students to be able to make important choices for and contribute to a sustainable transformation of our world. The intellectual aspect is essential for giving the commitment scientific rigor and a critical stance; an emotional involvement in sustainability issues is also essential if students are to become dedicated and want to do something. However, knowledge and emotions are not much use when it comes to a sustainable transformation if you do not know how to act. As such, Öhman and Sund argue that students need to be given an active role as producers of knowledge, and teachers, in turn, need to help them to develop their abilities and desires to play an active role in this transformation.

Within the five papers within this volume, the authors reflect on current trends in transformative pedagogies and transformational learning approaches to ESE, making the case for change and development in educational practice. More specifically, the papers illustrate a series of engagements with the attitudes of the teachers (or instructors) who are implementing transformative pedagogies, the tensions and emotional load that teachers experience when seeking to develop their professional identity in the context of ESE, and how learning through ESE-informed practice involves and is intimately connected with emotions. Rushton and Öhman and Sund both provide conceptual-empirical examples from teacher interviews when teachers in their practice enact ESE-informed curricula and approaches. McCullough and Pelcher also lend some empirical weight to transformative learning by reflecting on the experiences of an instructor and a student in a sport ecology course. Sund and Gericke and Casinder extend this to offer conceptual and philosophical analysis of the research and policy literature on ESE teaching and its different functions and characteristics. Although emerging from different contexts across Europe (Sweden and the UK), the United States of America and Australia, these common themes illustrate the critical role of policy and practice in shaping high-quality teacher education to support 
transformative ESE in classroom practice. However, in a complex and turbulent world, defined by intersecting challenges of environmental and social inequality and injustice, we suggest that future research in this area might help more clearly articulate what ESE has to contribute to these wider debates to make it truly transformative at a global level.

Institutional Review Board Statement: Not applicable.

Informed Consent Statement: Not applicable.

Data Availability Statement: Not applicable.

Conflicts of Interest: The authors declare no conflict of interest.

\section{References}

1. Evans, N. Implementing Education for Sustainability in Higher Education Through Student-Centred Pedagogies. In Routledge Handbook of Higher Education for Sustainable Development; Barth, M., Michelsen, G., Rieckmann, M., Thomas, I., Eds.; Routledge: Abingdon, UK, 2016; pp. 445-461.

2. Mezirow, J. Learning As Transformation: Critical Perspectives on A Theory in Progress; Jossey Bass: San Francisco, CA, USA, 2000.

3. Sterling, S. Transformative Learning and Sustainability: Sketching the conceptual Ground. In Learning and Teaching in Higher Education; Emerald Group Publishing: Bingley, UK, 2010; Issue 5; pp. 17-33.

4. Sterling, S. Higher education, sustainability, and the role of systemic learning. In Higher Education and the Challenge of Sustainability; Corcoran, P.B., Wals, A.E.J., Eds.; Kluwer: Dordrecht, The Netherlands, 2004; pp. 49-70.

5. Andreotti, V.D.O. The task of education as we confront the potential for social and ecological collapse. Ethics Educ. 2021, 16, 143-158. [CrossRef]

6. Mezirow, J. Transformative Dimensions of Adult Learning; Jossey-Bass: San Francisco, CA, USA, 1991. 